\title{
Transient Stability using FACTS Controller
}

\author{
Sandeep kaur \\ Asst.Professor, Department Of Electrical \& Electronics Engineering, \\ Chandigarh University,Gharuan(Mohali),Punjab, \\ Dr. Raja Singh Khela \\ Director-Principal \\ Doaba Group of Colleges ,Kharar ,Punjab,
}

\begin{abstract}
Transient stability is the ability of the power system to maintain synchronism when subjected to a severe transient disturbance. The resulting system response involves large excursions of generator rotor angles and is influenced by the nonlinear power-angle relationship. Stability depends on both the initial operating state of the system and the severity of the disturbance. Usually, the system is altered so that the post-disturbance steady-state operation differs from that prior to the disturbance. FACTS technology can facilitate power control, enhance the power transfer capacity, decrease the line losses, increase power system damping and improve the stability and security of the power system.
\end{abstract}

Keywords - Transient stability ,Synchronism, Rotor angles ,FACTS,Damping etc.

\section{INTRODUCTION}

In large power systems, transient instability may not always occur as first swing instability, it could be the result of several modes of oscillations causing large excursions of rotor angle beyond the first swing.Transient stability limits the available transfer capacity during the fault condition. Transient stability limit is the maximum power which can be transmitted during the transient state. Transient stability is important from the point of view of maintaining system security. In other words, incidence of a fault should not lead to tripping of generating unit due to loss of synchronism and the possibility of a cascaded outage leading to system black out.

Baker, M. H.etal in [1], suggested the advantages of FACTS controllers for power system stability. Cavaliere, C.A.C. Watanabe, E.H.etal in [2] suggested about static synchronous compensators (STATCOM) operating in electrical systems where the voltages are unbalanced and contain negative sequence components. De Assis, T.M.L., Watanabe, E.H.,Pilotto, L.A.S etal in [3] suggested a new technique to control reactive power oscillations using a multipulse STATCOM. It is shown that the voltage oscillations can be controlled in a simple way maintaining the STATCOM DC voltage constant.El Moursi, M.S., Sharaf, A.M. [4] suggested the dynamic operation of novel control scheme for both Static Synchronous Compensator (STATCOM) and Static Synchronous Series Compensator (SSSC) based on a new full model comprising a 48-pulse Gate Turn-Off thyristor voltage source converter for combined reactive power compensation and voltage stabilization of the electric grid network.Haque, M.H.etal in [5] suggested the feature of STATCOM and SSSC to improve the stability limit of a simple power system.

\section{CONTROLLABLE PARAMETERS FOR FACTS CONTROLLERS}

There are few basic points that are to be considered regarding the possibilities of power flow control. These are:

- Control of the line impedance X can provide a powerful means of current control.

- When the angle is not large, which is often the case, control of $\mathrm{X}$ or the angle substantially provides the control of active power.

- Control of angle which in turns control the driving voltage, provides powerful means of controlling the current voltage and hence active power flow when the angle is not large.

- Injecting a voltage in series with line, and perpendicular to the current flow, can increase or decrease the magnitude of the current flow. Since the current flow lags the driving voltage by 90 degree, this means injection of reactive power in series, can provide a powerful means of controlling the line current, and hence the active power when the angle is not large. 
- Injecting a voltage in series with line and with any phase angle with respect to the driving voltage can control the magnitude and the phase of the current. This means that injecting the voltage phasor with variable phase angle can provide powerful means of precisely controlling the active and reactive power flow; this requires the injection of both active and reactive power in series.

- When the angle is not large, controlling magnitude of one or the other line voltages can be a very cost effective means for the control of reactive power flow through the interconnection.

- Combination of the line impedance control with a series controller and voltage regulation with a shunt controller can also provide a cost effective means to control both the active power flow and reactive power flow between the two systems.

\section{Multi-Machine System Modeling}

The popular Western System Coordinated Council (WSCC) 3-machines 9-bus practical power system with loads assumed to be represented by constant impedance model.

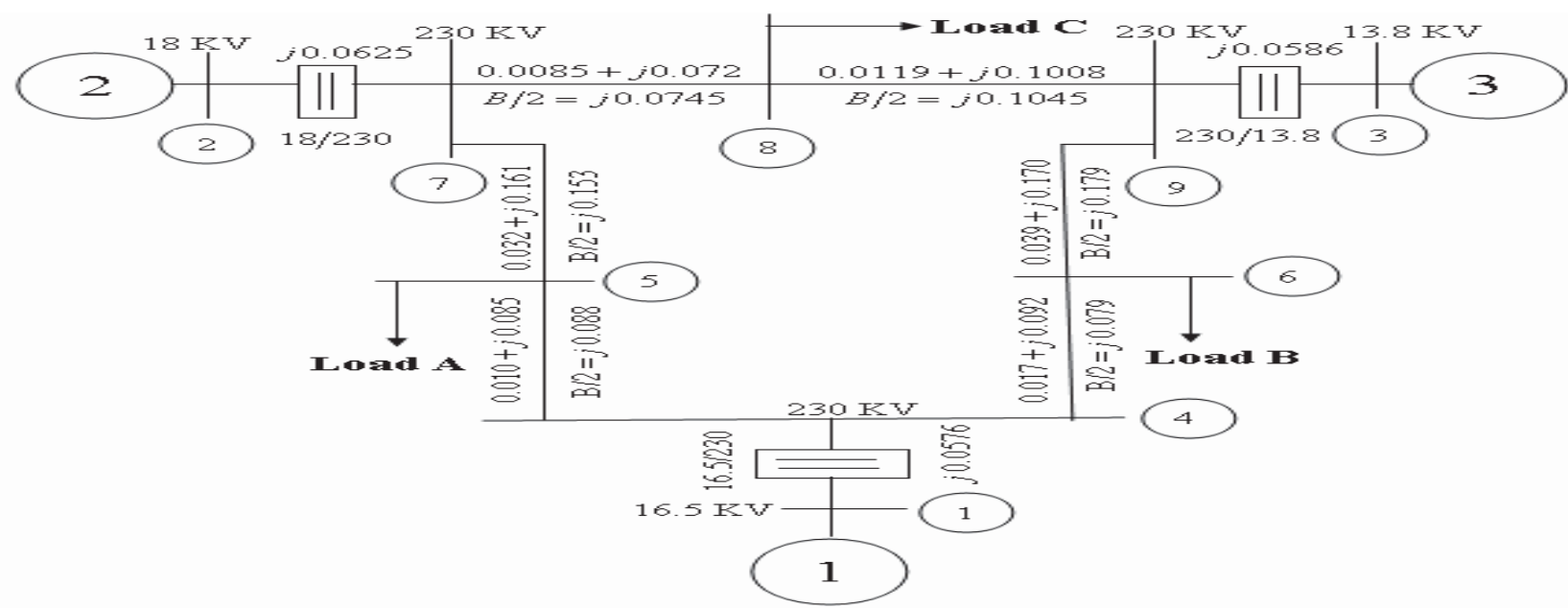

The base MVA of the system is 100 , and system frequency is $60 \mathrm{~Hz}$. The complete system been represented in terms of MATLAB/Simulink blocks. This model finds its utility for transient stability study the reason being power system configuration differs before fault and after fault. Multi-machine system with all the required components is modeled. The generator data is given in appendix A. All time constants are in seconds. 
IV.MATLAB/Simulink Model of Multi-Machine (3-Machine 9-Bus) System

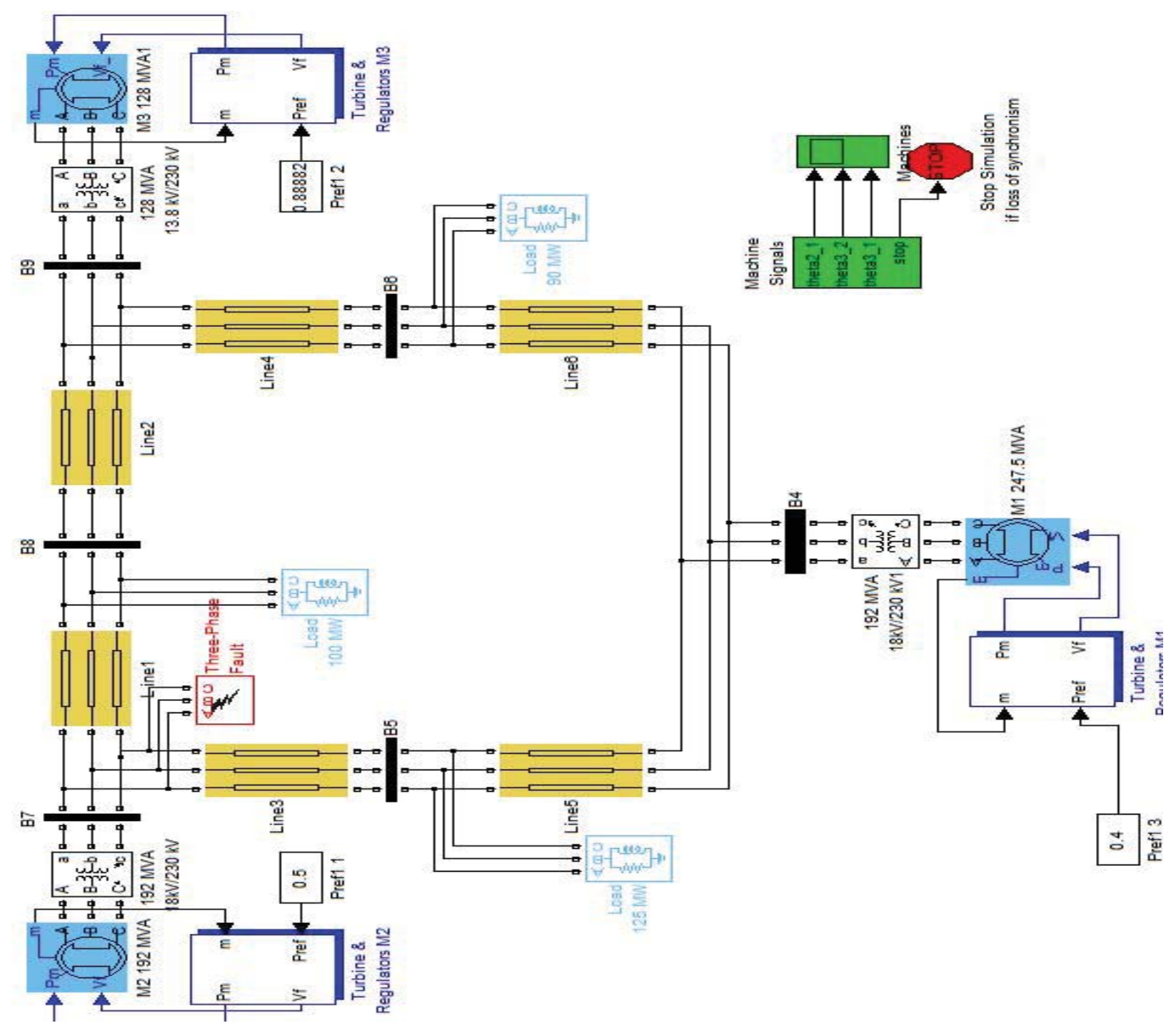

V. Simulation Results for Multi-Machine System

a) STATCOM is placed between Bus 6 and Bus 9 

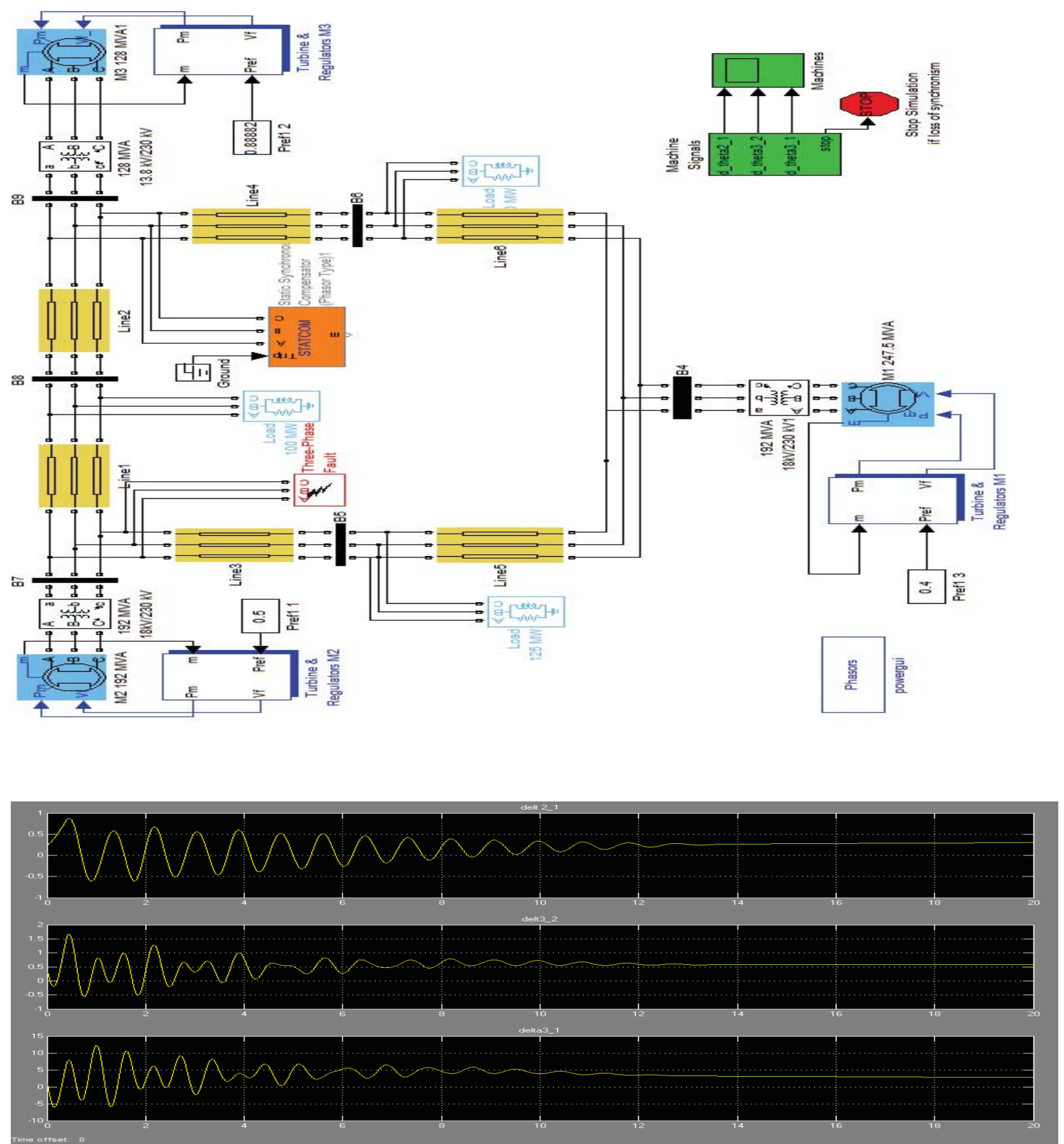

Figure shows the relative angular positions for delt2_1, delt3_2and delt3_1 for multi-machine system with STATCOM controller placed between Bus 9 and Bus 6 and fault taking place between Bus 5 and Bus 7.The total simulation time taken is $20 \mathrm{sec}$. 
Stability time for STATCOM placed between Bus 9 and Bus 6

\begin{tabular}{|c|c|c|c|c|}
\hline FAULT & STATCOM & Stability time for & Stability time for & Stability time for \\
\hline POSITION & POSITION & delt2_1 (in sec.) & delt3_2 (in sec.) & delt3_1 (in sec.) \\
\hline Between Bus & Between Bus 9 & 13.8 & 13 & 12 \\
\hline 5 \& Bus 4 & \& Bus 6 & & & \\
\hline
\end{tabular}

It is clear from the table that the time required by delt $3 \_1$ to get stable is minimum i.e 12 seconds

b) UPFC is placed between Bus 6 and Bus 9

Figure shows the relative angular positions for delt2_1, delt3_2and delt3_1 for multi-machine system with UPFC controller placed between Bus 9 and Bus 6 and fault taking place between Bus 5 and Bus 7.The total simulation time taken is $20 \mathrm{sec}$.

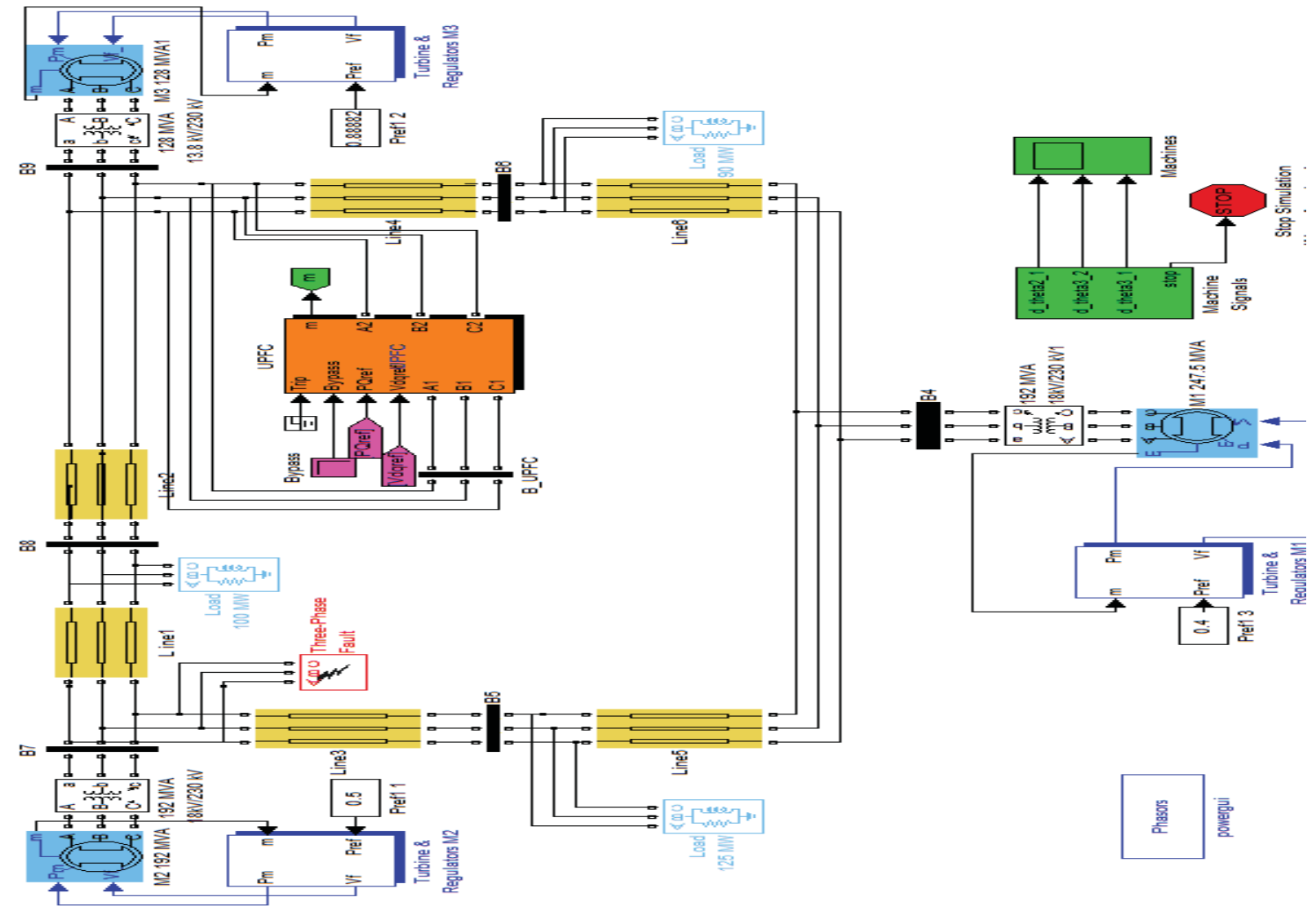




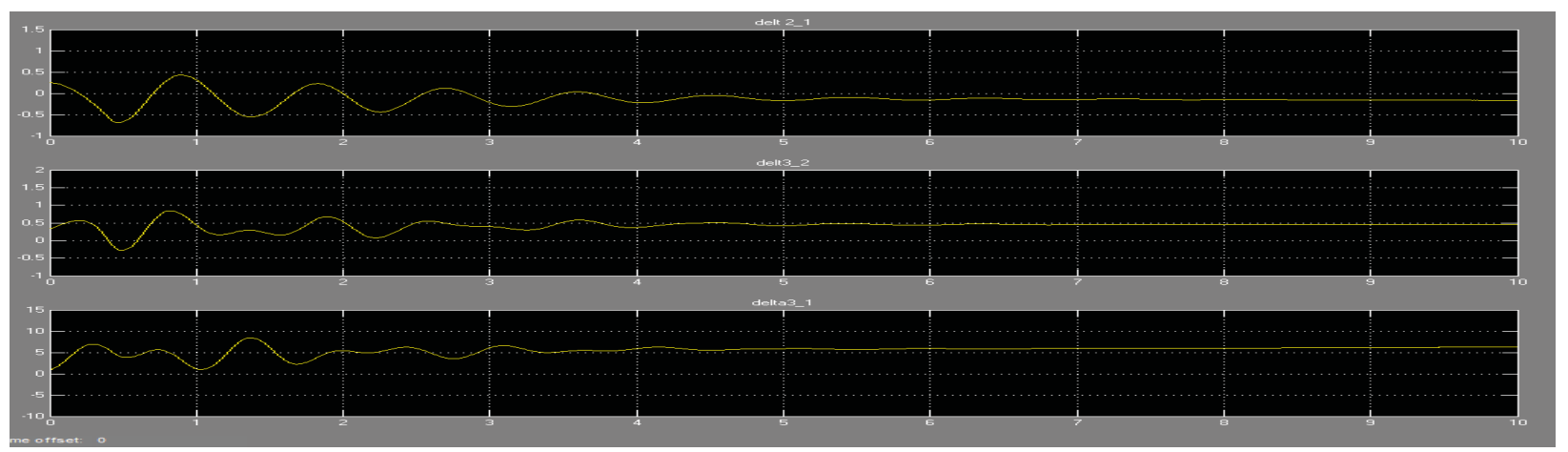

Stability time for UPFC placed between Bus 9 and Bus 6

$\begin{array}{lllll}\text { FAULT } & \text { STATCOM } & \text { Stability time for } & \text { Stability time for } & \begin{array}{l}\text { Stability time for } \\ \text { delt3_1 (in sec.) }\end{array} \\ \text { POSITION } & \text { POSITION } & \text { delt2_1 (in sec.) } & \text { delt3_2 (in sec.) } & 4.7 \\ \text { Between Bus 5 } & \begin{array}{l}\text { Between } \\ \text { \& } 6\end{array} & 5 & \\ \text { Bus } 4 & \begin{array}{l}\text { Bus } 9 \& \\ \text { Bus6 }\end{array} & & & \end{array}$

It is clear from the table that the time required by delt $3 \_1$ to get stable is minimum i.e 4.7 seconds

\section{VI.RESULT and ANALYSIS}

FACTS CONTROLLER

STATCOM

UPFC

\section{STATCOM \& UPFC POSITION :- Between Bus 9 \& Bus 6}

$\begin{array}{lcc}\text { Stability time for delt2_1(in sec) } & 13.8 & 6 \\ \text { Stability time for delt3_2(in sec) } & 13 & 5 \\ \text { Stability time for delt3_1(in sec) } & 12 & 4.7\end{array}$

\section{VII.CONCLUSION}

The power system stability enhancement of a 3-machine 9 bus system by station \& UPFC is compared and discussed. The dynamics of the system is compared with the presence of STATCOM \& UPFC in the system in the event of a major disturbance. Then the performance of UPFC for power system stability improvement is compared with the STATCOM. It is clear from the simulation results that there is a considerable improvement in the system performance with the use of UPFC for which settling time in post fault is found to be around $4.7 \mathrm{sec}$. The optimum location of the UPFC is found to be when it is connected between buses 9 and 6 .

\section{REFERENCES}

[1] Baker, M. H., September 1995 "An Assessment of FACTS Controllers for Transmission System Enhancement," CIGRE SC 14 International Colloquium on HVDC \& FACTS, Montreal.

[2] Cavaliere, C.A.C. Watanabe, E.H.Aredes, M.2002“ Multi-pulse STATCOM Operation Under Unbalanced Voltages”, Proceedings of the IEEE Power Engineering Society Winter Meeting, 2002.,Vol.1, pp 567- 572, 2002.

[3] De Assis, T.M.L.,Watanabe, E.H.,Pilotto, L.A.S, Sollero, R.B 2002.“A New Technique to Control Reactive Power Oscillations using STATCOM" Proceedings of the IEEE International Conference Harmonics and Quality of Power ,Vol.2, pp 607-613

[4] El Moursi, M.S., Sharaf, A.M., 2005 "Novel Controllers for the 48-pulse VSC STATCOM and SSSC for Voltage Regulation and Reactive Power Compensation“Proceedings of the IEEE Power Systems, Vol 20,Issue 4, pp 1985- 1997,. 
[5] Haque, M.H., 2005. "Stability Improvement by FACTS Devices- A Comparison between STATCOM and SSSC", Proceedings of the IEEE Power Engineering Society General Meeting, , Vol. 2, pp 1708- 1713.

[6] Huwag A.F,Bashi S.M,Marium N,2004 "A STATCOM Simulation Model to Improve Voltage Sag Due to Starting of High Power Induction Motor" Proceedings of the IEEE National Power and Energy Conference (PE Con 2004), pp 148-152.

[7] Jianye Chen,Shan Song, Zanji Wang 2006 "Analysis and Implement of Thyristor-Based STATCOM", Proceedings of the IEEE International Conference Power System Technology,(Power Con2006). pp 1-5

[8] K.R. Padiyar,2002 "FACTS Controllers in Power Transmission and Distribution", New Age International (P) Limited, Publishers.

[9] Kundur. P, Paserba. J, Ajjarapu. V, Andersson. G, Bose. A, Canizares. C, Hatziargyriou. N, Hill. D, Stankovic. A, Taylor. C, Cutsem. T. U, Vittal. V,2004 "Definition and Classification of Power System Stability," IEEE Trans. on PowerSystems, Vol. 19, pp 1387-1401.

[10] Li Chun, Jiang Qirong,Xu Jianxin2000“ Investigation of Voltage Regulation Stability of Static Synchronous Compensator in Power System", Proceedings of the IEEE Power Engineering Society Winter Meeting, 2000,Vol.4, pp 2642-2647.

[11] Mahajan Vasundhara Oct 2008"Power System Stability Improvement with Flexible AC Transmission System (FACTS) Controller" Proceedings of IEEEPower India Conference (POWERCON 2008), pp 1-7.

[12] Murali D, Rajaram M,2009“Transient Energy Analyis for STATCOM and SSSC Application" International Journal of Electrical and Power Engineering, Vol 3, Issue 4, pp 191-197.

[13] Murali D, Rajaram M,2009“Transient Energy Analyis for STATCOM and SSSC Application” International Journal of Electrical and Power Engineering, Vol 3, Issue 4, pp 191-197. 